Illinois State University

ISU ReD: Research and eData

Theses and Dissertations

3-19-2015

\title{
Associations between physical activity and weight status with grade-school performance
}

Taylor Panfil

Illinois State University, tpanfil3@gmail.com

Follow this and additional works at: https://ir.library.illinoisstate.edu/etd

Part of the Epidemiology Commons, and the Kinesiology Commons

\section{Recommended Citation}

Panfil, Taylor, "Associations between physical activity and weight status with grade-school performance" (2015). Theses and Dissertations. 363.

https://ir.library.illinoisstate.edu/etd/363

This Thesis is brought to you for free and open access by ISU ReD: Research and eData. It has been accepted for inclusion in Theses and Dissertations by an authorized administrator of ISU ReD: Research and eData. For more information, please contact ISUReD@ilstu.edu. 


\title{
ASSOCIATIONS BETWEEN PHYSICAL ACTIVITY AND WEIGHT STATUS WITH GRADE-SCHOOL PERFORMANCE
}

\author{
Taylor E. Panfil
}

56 Pages

May 2015

Physical activity and weight status are predictive of childhood health, but more recent research suggests they may also be associated with academic success.

PURPOSE: To explore the relationships between physical activity, weight status, and academic performance in children, accounting for parental education level.

METHODS: 614 third-to-fifth grade children (53.9\% female, age $9.6 \pm 0.9$ years) from two Midwestern communities participated. Physical activity was assessed using a Digiwalker 200-SW pedometer worn for seven consecutive days. Teachers provided an estimate of general academic performance, and children were categorized into three performance groups (high, moderate, low). School behavior (attentiveness, staying on task, interruptive behavior) was assessed by the teacher. Weight status (normal weight, overweight, obese) was determined by body mass index percentile. Logistic regression was used to analyze the relationships among physical activity, weight status, self-reported parental education level, and academic performance.

RESULTS: Approximately 1 in 3 children were overweight or obese (29.6\%). Nearly half (44.6\%) of the subjects averaged $\geq 12,000$ steps per day, meeting physical activity recommendations. A crude logistic model revealed obesity was predictive and physical 
activity was not predictive of being in the moderate/low academic performance groups, odds ratio $(\mathrm{OR}[95 \% \mathrm{CI}])=1.88(1.1-3.3)$ and $1.0(0.7-1.4)$, respectively. However, parental education was a stronger predictor, where those with parents who attended high school, some college, or obtained a two-year college degree being more likely to be in the moderate/low academic performance group, $\mathrm{OR}=3.1$ (1.5-6.5), 2.9 (1.6-5.2), and 2.4 (1.3-4.4), respectively. In a full model, including weight status, physical activity, and parental education, the latter attenuated the impact of obesity. Parental education remained significant, $\mathrm{OR}=3.0(1.4-6.2), 2.8$ (1.5-5.0), and $2.3(1.2-4.2)$ for those who attended high school, some college, and obtained two-year degree, respectively. In a full model, including physical activity, weight status, parental education, and school behavior variables, not meeting physical activity recommendations was predictive of less interruptive behavior, whereas those with parents who attended high school were more likely to interrupt others, $\mathrm{OR}=0.7(0.5-0.9)$ and $2.1(1.1-4.2)$, respectively. CONCLUSION: Weight status, and not physical activity, was predictive of academic performance, with obese children being approximately two-times less likely to receive higher grades compared to normal weight children. When accounting for parental education, neither weight status nor objectively measured physical activity were associated with grade-school performance. Though physical activity was not associated with academic performance overall, less active children were less likely to disturb others. However, parental education level was the strongest predictor of grade-school performance and classroom behavior in all analyses. 


\section{ASSOCIATIONS BETWEEN PHYSICAL ACTIVTY AND WEIGHT STATUS WITH GRADE-SCHOOL PERFORMANCE}

TAYLOR E. PANFIL

A Thesis Submitted in Partial Fulfillment of the Requirements for the Degree of

MASTER OF SCIENCE

School of Kinesiology and Recreation

ILLINOIS STATE UNIVERSITY 
(C) 2015 Taylor E. Panfil 


\section{ASSOCIATIONS BETWEEN PHYSICAL ACTIVITY AND WEIGHT STATUS WITH GRADE-SCHOOL PERFORMANCE}

TAYLOR E. PANFIL

COMMITTEE MEMBERS:

Kelly R. Laurson, Chair

Dale D. Brown

Margo M. Coleman 


\section{ACKNOWLEDGMENTS}

I would like to thank the owners of the SWITCH data set for granting me permission to utilize the data for the completion of this thesis. I would also like to thank Dr. Laurson for all of his help and pushing me to do my best. Thank you to Dr. Brown and Dr. Coleman for their insight and guidance. Finally, I would like to thank my family and friends for their patience, support, and stress-relief.

T.E.P. 


\section{CONTENTS}

\section{Page}

ACKNOWLEDGMENTS $\quad$ i

CONTENTS

TABLES $\quad$ iv

FIGURES $\quad$ V

\section{CHAPTER}

I. REVIEW OF RELATED LITERATURE 1

Introduction 1

Activity Monitors Measures and Academic Performance 3

FITNESSGRAM Measures and Academic Performance 10

$\begin{array}{ll}\text { Physical Education and Academic Performance } & 18\end{array}$

Weight Status and Academic Performance $\quad 19$

Physical Activity, Weight Status, and School Behavior 22

Conclusion $\quad 30$

$\begin{array}{lll}\text { II. INTRODUCTION } & 31\end{array}$

$\begin{array}{ll}\text { Purpose } & 35\end{array}$

III. METHODOLOGY 36

$\begin{array}{ll}\text { Participants } & 36\end{array}$

Anthropometry $\quad 37$

Physical Activity $\quad 37$

Academic Performance 38

Socioeconomic Status $\quad 39$

Statistical Analysis $\quad 39$

$\begin{array}{lll}\text { IV. RESULTS } & 40\end{array}$ 
$\begin{array}{ll}\text { V. DISCUSSION } & 46\end{array}$

$\begin{array}{ll}\text { Limitations } & 52\end{array}$

VI. CONCLUSION 53

$\begin{array}{ll}\text { REFERENCES } & 54\end{array}$ 


\section{TABLES}

Table $\quad$ Page

1. Sample Descriptive Statistics 37

2. Descriptive Frequencies 40

3. Full Logistic Regression Model of Physical Activity, Weight Status, and Moderate/Low Academic Performance Defined by Teacher Grade

4. Full Logistic Regression Model of Physical Activity, Weight Status, and School Behavior Variables by Gender

5. Full Logistic Regression Model of Physical Activity, Weight Status, and Tendency to Interrupt Other Children's Work 


\section{FIGURES}

Figure

Page

1. Distribution of Children in the High Academic Performance Group Based on Predictor Variable

2. Distribution of Children Who Have No Difficulty With School Behaviors Based on Predictor Variable 


\title{
CHAPTER I
}

\section{REVIEW OF RELATED LITERATURE}

\author{
Introduction
}

It is estimated that $22-39 \%$ of U.S. youth are sufficiently active according to the current physical activity recommendations of partaking in at least 60 minutes of physical activity on each day of the week (6). In a sample of 811 U.S. youth, children were sedentary an average of $6 \mathrm{hr} / \mathrm{day}^{-1}$, as defined by generating less than 100 activity counts/minute while wearing an Actigraph accelerometer, which increased into adolescence by approximately $2 \mathrm{hr} / \mathrm{day}^{-1}(20)$. Along with these physical inactivity inclinations, the prevalence of overweight and obese youth has increased in recent years. It is estimated that $31.8 \%$ of children and adolescents ages $2-19$ are overweight or obese according to the 2011-2012 National Health and Nutrition Examination Survey (5). This prevalence has increased from $30 \%$ in $2005-2006,28.1 \%$ in $1999-2000$, and $23.0 \%$ in 1988-1994. These increases are due to the rising prevalence in obesity $(10.0 \%$ in 1998 $1994,13.9 \%$ in $1999-2000,15.4 \%$ in $2005-2006$, and $16.9 \%$ in $2011-2012$ ) as the frequency of overweight children and adolescents remained stable. The occurrence of overweight/obesity follows the trend of inactivity by increasing with age as $8.4 \%, 17.7 \%$, and $20.5 \%$ of children ages $2-5$, children ages $6-11$, and adolescents ages 12-19, 
respectively, were obese in 2011-2012 (5). The prevalence of overweight/obesity in youth has been shown to track into adulthood as well. In a sample of 854 U.S. children, approximately $80 \%$ of those who were overweight during adolescence were obese in young adulthood (21-29 years of age) (28). The odds of adulthood obesity increased with each subsequent age range as obese children ages 6-9 and adolescents ages 10-14 were 10.3 and 28.3 times more likely to be obese as adults, respectively, compared to children/adolescents of a normal weight status. Obesity in childhood can also lead to chronic diseases in adulthood. In a study utilizing 745 children and adolescents (mean age $=12.7$ years), weight status was the strongest predictor of developing clustering of metabolic syndrome risk factors (high body mass index (BMI), fasting insulin, systolic blood pressure, and total cholesterol to HDL cholesterol ration) in adulthood (25). Children in the top BMI quartile were 11.7 times more likely to develop clustering in adulthood compared to children in the lowest BMI quartile. Coronary heart disease in adulthood has been linked to childhood obesity as well as the risk for coronary heart disease increased with subsequent increases in BMI and age for boys and girls (2). To add to these problems, opportunities for physical activity are being removed from schools. In 2006, approximately $4 \%$ of elementary schools, $8 \%$ of middle schools, and $2 \%$ of high schools provided daily physical education (17).

Regular physical activity is a preventive measure in youth to decrease the risk of obesity along with other chronic diseases. Along with the many health benefits of physical activity, cognitive benefits have been examined as well. Habitual physical activity has been found to have a positive association with cerebral blood flow and cognitive performance in healthy individuals (13). Volunteer physical activity in rats has 
demonstrated short- and long-term increases in the quantity and regulation of brainderived neurotrophic factor (BDNF), which enhances learning and cognition (8). In children ages 9-10, higher aerobic fitness levels, as defined by a higher $\mathrm{VO}_{2 \max }$ value, were associated with increases in hippocampal volume, which plays an important role in memory recall (7). Further, integrating 30 minutes of physical activity a day, 3 days a week into the classroom curricula for approximately 12 weeks resulted in significantly better general intelligence and cognitive ability test scores compared to children not receiving physical activity in the classroom (23).

The associations between physical activity, weight status, and academic performance, including classroom behaviors such as attentiveness, time-on-task, and disruptive behavior, have been researched in recent years in children and adolescents. This research has yielded inconsistent results and utilized various methods in measuring each variable. The aim of this review is to analyze the past research on physical activity, weight status, and academic performance in children and adolescents.

Activity Monitor Measures and Academic Performance

Activity monitors are the criterion-referenced standard for physical activity measurement in this research because it is a direct measure of an individual's physical activity. Accelerometers and pedometers are monitors that are commonly used as objective measures in research. Pedometers are worn on an individual's hip and measure the amount of steps taken in a given period of time. Accelerometers measure steps as well as the metabolic equivalents (METs) of the activity. Activity levels can then be quantified based on intensity (light, moderate, and vigorous). These monitors will yield more objective and accurate assessments of subjects' physical activity as opposed to self-report 
measures, such as physical activity questionnaires. Few studies to date have utilized objective measures of physical activity in examining the relationship between physical activity, weight status, and academic performance. In those studies utilizing activity monitors, mixed results have been found.

Reed et al. (23) examined the impact of integrating physical activity with the elementary curriculum on academic performance. Subjects were 155 randomly selected $3^{\text {rd }}$ grade students from 6 classrooms. 3 of the classrooms were randomly assigned to the Control Group $(\mathrm{CG})(\mathrm{n}=75 ; 56 \%$ male $)$, and 3 classrooms $(\mathrm{n}=80 ; 57 \%$ male $)$ were randomly assigned to the Experimental Group (EG). Fundamental skills, such as running, hopping, and walking, were incorporated into the EGs' core classes (Language Arts, Math, Social Studies, and Science) approximately 30 minutes a day, 3 days a week for 3 months. Teachers of the EG classrooms partook in 2 training sessions prior to and 2 sessions during the study on how to integrate physical activity into their lessons. Random observations by the researchers were conducted to ensure procedures were being followed. Physical activity in the EG was assessed via a Yamax New Lifestyles DigiWalker SW-200 pedometer, which was worn on the subjects' hip, during each integrated lesson. The pedometer was set to zero before each lesson, and steps were recorded by the teacher following each lesson. Physical activity outside of school and the subjects' perceptions of physical activity were assessed using the Previous Day Physical Activity Recall (PDPAR), which was administered during the first and last week of the study. A standardized statewide test, Palmetto Achievement Challenge Test (PACT), was used as a measurement of academic achievement. This was administered one week after the final day of the intervention. 
Subjects in the EG averaged 1,146 steps (standard deviation $[\mathrm{SD}]=356$ steps) each intervention day. Subjects in the EG had a greater percentage receive "Proficient" and "Advanced" marks in all subject areas on the PACT than subjects in the CG. Significant differences between the groups were found only for the Social Studies PACT scores, $t=2.936, p=0.004$. In regards to the PDPAR, both groups exhibited increases in physical activity from the initial administration to the second administration of the PDPAR. Despite the increases, there were no significant differences between groups at both administration periods.

Integrating physical activity into the classroom can have positive effects on academics. Though significant differences were found only for the Social Studies test scores, greater percentages of subjects in the EG received higher scores in all test areas. Reed et al. (23) used a control group which helps to strengthen the results and serves as a comparison for the experimental group. A limitation to this study is that pre- and post-test comparisons could not be computed for the PACT scores because this test does not begin until $3^{\text {rd }}$ grade. The researchers found no significant main effect differences or betweensubject effects pre-intervention for the EG and CG by gender, BMI, age, and ethnicity. Therefore, the researchers felt confident making the above comparisons.

Kwak et al. (15) explored the associations between different intensity levels of physical activity and academic achievement. It was also examined if cardiovascular fitness was a mediator in the physical activity-academic achievement relationship. Subjects were $2329^{\text {th }}$ grade students (15-16 years old; 120 females) from 14 randomly selected schools in Sweden. Academic achievement was assessed via grades for 17 school subjects. There are 4 categories of credit points for each subject $(0,10,15$, and 
20), and the sum of the grades for each subject was used as the dependent variable.

Subjects wore a WAM 7164 accelerometer on the right hip for a minimum of 10 hours per day for 4 consecutive days with at least 1 day being a weekend day. MET values were calculated using the Trost equation, which takes into account steps counts per minute, to classify activity as being light ( $<3$ METs), moderate (3-6 METs), or vigorous $(\geq 6$ METs). Subjects' cardiovascular fitness was quantified as their maximal power output on a cycle ergometer. Workload was increased by 50 watts for boys and 40 watts for girls every 3 minutes until exhaustion. Differences between intensity levels, as well as sex, were analyzed and linear regression analysis was conducted. Potential cofounders, such as mother's education level, family structure, and parental monitoring, were included in the regression analysis.

For girls, only vigorous physical activity was significantly associated with academic achievement $(r=0.30, p<0.01)$. The association remained significant with the inclusion of fitness $(\mathrm{r}=0.23, p<0.05)$, and explained variance in academic achievement increased from $26 \%$ to $29 \%$. Adding fitness as a variable in the regression model shows that fitness is not significantly associated with academic achievement. Therefore, the vigorous activity-academic achievement association is not mediated by fitness. With the potential confounders included in the analysis, the physical activity and academic performance association maintained significance. For boys, academic achievement was significantly associated with pubertal phase (genital development), $\mathrm{r}=0.25, p<0.05$. With the inclusion of fitness, only fitness was significantly associated with academic achievement $(\mathrm{r}=0.25, p<0.05)$, and explained variance increased from $26 \%$ to $30 \%$. 
Kwak et al. (15) pinpointed a specific intensity level for girls that is correlated with better grades. In girls, participating in more frequent vigorous physical activity is associated with academic achievement. Though the association was significant, the strength of association was low-to-moderate. For boys, a significant association was not found between intensity level and academic achievement. This can be due to different physiological and psychological mechanisms, such as brain growth factors and selfesteem, in boys and girls, even though boys participated in significantly more vigorous physical activity per day (boys $=16 \min [\mathrm{SD}=12], p<0.01$; girls $=12 \min [\mathrm{SD}=11]$ ). Cardiovascular fitness was significantly associated with academics in boys but not girls. This shows that boys who are more physically fit in terms of cardiovascular fitness tend to do better academically. The non-significant association in girls can be due to their low average fitness level, 170 watts $(\mathrm{SD}=29.9)$.

The inclusion of potential confounders in this study helps to strengthen the results. It shows that the relationship between intensity level/cardiovascular fitness and academic achievement is not mediated by socioeconomic variables. In using a direct measurement of physical activity, these results may be more superior to those studies using self-report measures. A limitation in using accelerometers, though, is activities such as cycling and swimming are not measured. Therefore, the subjects' activity time may be underestimated. Also, measuring 1 week, or in this instance, 4 days, may not be sufficient enough to depict the subjects' actual activity patterns. Finally, the cross-sectional study design disallows casual conclusions of the physical activity-academic achievement relationship from being drawn. Therefore, it cannot be concluded whether more time 
spent participating in vigorous physical activity in girls or having better cardiovascular fitness in boys results in academic success.

LeBlanc et al. (16) and Syväoja et al. (26) conducted cross-sectional studies utilizing the ActiGraph GT1M and objective academic achievement measures to examine the physical activity-academic achievement relationship that yielded similar results. LeBlanc et al. (16) conducted their study with $4^{\text {th }}-6^{\text {th }}$ grade students $(n=261)$ from rural Louisiana schools. The sample was $66.3 \%$ female and 76.3\% African American. Academic achievement was measured by criterion-referenced standardized tests, which tested the students in English/language arts, mathematics, science, and social studies. These tests are given annually, and scores were obtained from the Louisiana Department of Education. Physical activity was assessed via an ActiGraph GT1M accelerometer, which was worn over 3 consecutive weekdays. Inclusion criteria for the ActiGraph included at least 10 hours of wear time a day, which excluded consecutive zeroes, erroneous data, and self-reported sleep time, and at least 2 complete days of wear. Step counts per minute were used in the Trost equation to determine the intensity of physical activity. Moderate and vigorous activity were combined (MVPA) into one category. MVPA was calculated as step counts greater than 100, and sedentary behavior (SED) was calculated as counts less than 100. The subjects' free/reduced lunch status (130-185\% below the poverty line) was utilized as a potential confounding variable.

Syväoja et al. (26) utilized 277 volunteer $5^{\text {th }}$ and $6^{\text {th }}$ grade students (154 female) from 5 Finnish schools. Students' grade-point average (GPA), which was provided by the education services in the schools' city, was used as the measurement of academic achievement. The Finnish GPA scale is from 5-10, with 5.0-5.9 equaling a 1.0 in United 
State GPA and 9.0-10.0 equaling a 4.0. Physical activity was assessed via the Actigraph GT1M accelerometer, which was worn on the subjects' right hip for 7 consecutive days. Data was included if the subjects wore the accelerometer for at least $500 \mathrm{~min} \cdot \mathrm{d}^{-1}$ on 2 weekdays and 1 weekend day. Intensity of physical activity was measured via step counts per minute. 2296 counts per minute was considered MVPA, and the criteria for sedentary time was the same as LeBlanc et al. (16). Children were classified into groups depending on the amount of measured MVPA ( $\leq 47 \mathrm{~min}, 47.1-65.0 \mathrm{~min}$, and $\geq 65.1 \mathrm{~min})$ and sedentary time $(\leq 38.4 \%, 38.5 \%-41.4 \%$, and $\geq 41.5 \%)$ per day. Parental education level was included in the analysis as a potential confounder.

Both studies found no associations between MVPA or SED and academic achievement after controlling for their respective socioeconomic (SES) variables. In LeBlanc et al. (16), bivariate correlations between MVPA and each academic test resulted in $\mathrm{r}=-0.15,-0.09,-0.11$, and -0.08 for English/language arts, math, science, and social studies, respectively. Very weak associations were also found between SED and English/language arts, math, science, and social studies, $r=0.11,0.05,0.06$, and 0.07 , respectively. Free/reduced lunch status was found to be significantly correlation with academic test achievement $(r=0.19-0.28)$. Correlations in Syväoja et al. (26) showed no significant association between MVPA $(p=0.955)$ or sedentary time $(p=0.285)$ and GPA. The ANOVA examining associations between physical activity, sedentary behavior, and academic achievement also revealed no significant associations between $\operatorname{MVPA}\left(\mathrm{F}_{2,216}=0.17, p=0.843\right)$ or sedentary time $\left(\mathrm{F}_{2,216}=0.46, p=0.635\right)$ and GPA. As with LeBlanc et al. (16), SES, as measured by parental education level, had a significant correlation with academic achievement $(\mathrm{r}=0.25)$. 
Despite minor differences in methodology (i.e. different accelerometer weartimes, academic achievement measures, etc.), the results of these studies utilizing the same accelerometer are similar. The use of an accelerometer, for reasons previously stated, strengthen the results of these studies. These studies were also conducted with subjects from different parts of the world, further strengthening the generalizability that there is no relationship between physical activity and academic performance. The use of different SES variables as confounders shows that SES can be a predictor of academic achievement, though the correlations were weak. Limitations of these studies are similar to those in Kwat et al. (15) including the inability for accelerometers to measure certain activities that involve little body displacement, shorter length of accelerometer wear-time, and the cross-sectional study design.

Objectively measured physical activity has resulted in different associations, or lack thereof, with academic performance. In being a more true representation of individuals' habitual physical activity, these associations should be clearer in order to establish the actual benefits of physical activity on academic performance.

\section{FITNESSGRAM Measures and Academic Performance}

FITNESSGRAM is a criterion-based physical fitness assessment that is completed during physical education classes each year. The assessment consists of 6 independent tests: mile run or PACER test (aerobic capacity), skin folds or body mass index (BMI) (body composition), curl-ups (abdominal strength), trunk lift (trunk extensor strength and flexibility), push-ups (upper body strength and endurance), and shoulder stretch or sit-and-reach test (flexibility). The tests are scored using the FITNESSGRAM software, which classifies scores into "meets" or "does not meet" based on the 
established Healthy Fitness Zone (HFZ) for the individual's gender and age. Scoring 5 of the 6 components in the HFZ constitutes as passing the battery overall. FITNESSGRAM is a valid and reliable assessment for aerobic capacity, muscular fitness, and body composition $(4,27)$. FITNESSGRAM assessments have been used frequently in research as a measure of physical activity in the physical activity-academic achievement relationship. Some researchers have utilized all of the assessments in their measurements, and others have only examined individual tests, the most frequent of which are assessments of aerobic capacity and body composition. Results of these studies have been more consistent than those utilizing activity monitors and mostly show a positive relationship between physical activity and academic achievement.

Van Dusen et al. (27) examined the associations between each FITNESSGRAM assessment and standardized test scores in youths and adolescents and found all assessments to be associated with standardized test scores. Van Dusen et al. (27) conducted their research using secondary data collected by 13 Texas school districts for the Texas Education Agency in the 2007-2008 school year. This resulted in a final convenience sample of 254,743 subjects (51.3\% female; $53.3 \%$ Hispanic) in grades 3-11 with at least 1 fitness test score and standardized test score. The fitness components were examined individually and results were also categorized by quintiles. Academic performance was assessed via reading and mathematics scale scores from the Texas Assessment of Knowledge and Skills (TAKS) as these two tests are administered to each grade.

Van Dusen et al. (27) found all fitness variables to have significant, positive associations with TAKS scores after controlling for ethnicity, grade-level, and school 
lunch status. Cardiovascular fitness had the strongest association with test scores with a test mean difference effect size of 0.17 (95\% CI: 0.15-0.19) followed by curl-ups, pushups, sit and reach, and trunklift. The associations between each fitness variable and math scores were stronger than for reading scores. In girls, there was a stronger relationship between fitness and reading scores than in boys. There was a dose-response relationship between TAKS scores and cardiovascular fitness quintile. When split by grade-level, there was a weak, non-significant association between cardiovascular fitness and TAKS scores in elementary-aged children. Cardiovascular fitness and TAKS scores developed a stronger relationship as grade-level increased.

This study shows there is a significant association between each FITNESSGRAM assessment (with the exclusion of BMI as it will be discussed later) and standardized test achievement. Also, girls were found to have a stronger fitness-academic relationship than boys. This is similar to Kwak et al. (15) who found physical activity to be associated with academic performance in girls but not boy when using an objective measure of physical activity. The non-significant associations between elementary school fitness levels and TAKS scores may be due to a lower test reliability as mentioned by the researchers. Limitations include the wider range of ages used in the study which decreases generalizability of the results. Also, connections between physical activity levels and academic performance cannot be made as in studies using objective measures of physical activity. Finally, motivation and self-esteem can play a major role in physical activity assessments, especially when completed around other students. Students may not put forth a maximal effort and assessment results can be an underrepresentation of their fitness levels. 
London and Castrechini (18) examined the associations between each FITNESSGRAM battery, collectively and individually, and academic performance initially and overtime. Secondary data from the Youth Data Archive in California, which is a longitudinal tracking system following K-12 public school students, was utilized. Data was combined from 2 school districts from the 2002-2003 to 2007-2008 school years. 2 cohorts were utilized, one consisting of $1,3254^{\text {th }}-7^{\text {th }}$ grade students and one consisting of $1,4106^{\text {th }}-9^{\text {th }}$ grade students. Physical fitness was measured by the California Physical Fitness Test (PFT), or FITNESSGRAM, which was taken in $5^{\text {th }}, 7^{\text {th }}$, and $9^{\text {th }}$ grade. The components were examined collectively and with BMI separate. The researchers examined initial academic achievement gaps as well as growth trajectories. Therefore, students' PFT pass and fail trajectories were examined by dividing them into one of four groups, "pass the PFT in both academic years", "pass the PFT in the first year but not the second", "pass the PFT in the second year but not the first", and "do not pass the PFT in either year". Academic achievement was measured by students' math and English language arts (ELA) scores on the California standardized test (CST), which is taken each spring, and results were converted to z-scores for the statistical analysis as the scores are not compatible across grades/years.

London and Castrechini (18) found an initial achievement gap existed prior to the first physical fitness assessment measured in each cohort. In the first cohort, $4^{\text {th }}$ grade students who passed both PFTs or failed in the first year but passed in the second year had significantly higher math and ELA scores compared to those who failed both PFTs. In the older cohort, a similar initial achievement gap was found between those passing and failing both PFTs. The CST growth trajectories for each of the 4 PFT groupings in 
each cohort were not statistically different overtime, showing the initial CST score achievement gap persisted. When split by gender, the same initial CST gap and CST growth trajectory results were found for each gender in both cohorts, but the differences in scores were more pronounced in girls.

The initial gaps that existed in London and Castrechini (18) show there is a stronger relationship for fitness and initial achievement than changes in both variables overtime. Being physically active at an earlier age can be more beneficial than making lifestyle changes later in adolescence. As with the previous study, motivation can be an underlying mechanism in FITNESSGRAM performance.

Several cross-sectional studies have found aerobic fitness to be associated with standardized test achievement. Castelli et al. (4) conducted their study using $2593^{\text {rd }}$ and $5^{\text {th }}$ grade students from 4 public elementary schools. The FITNESSGRAM assessments completed were the PACER, push-ups, curl-ups, and sit-and-reach, all of which were completed across 3 days. Tests were scored as being in the HFZ or non-HFZ. Academic achievement was assessed via the Illinois Standards Achievement Test (ISAT), specifically the math, reading, and total achievement scores, which is completed across a 5-day period. Age, sex, school, and poverty index were included in the regression analyses as covariates. The 3 FITNESSGRAM assessments and total fitness (the FITNESSGRAM assessment scores collectively) had positive correlations with each academic test measure $(p<0.1)$. In full regression models including each FITNESSGRAM subset, poverty index, age, school, and sex, PACER scores were significantly associated with greater total academic achievement scores, reading 
achievement, and math achievement, all $p<0.001$, whereas muscular strength and flexibility were not.

A similar study conducted by Bass et al. (3) examined the association between the FITNESSGRAM assessments and ISAT reading, math, and total achievement scores in 838 middle school students. Approximately $65-91 \%$ of students were in the HFZ for each fitness assessment. Correlations were significant but weak for each gender for PACER laps and sit-ups $(0.12-0.21,0.16-0.27$, and $0.15-0.25$ for reading, math, and total score, respectively). Girls had slightly stronger correlations between PACER laps and each test score than boys and had significant correlations between push-ups and test scores. In an adjusted model controlling for free/reduced lunch status and age, girls in the HFZ for the PACER were 2.08 and 2.58 times more likely to score higher on the reading and math tests, respectively, than girls not meeting the aerobic fitness standards. Boys in the PACER HFZ were 3.15 and 2.81 times more likely to succeed on the reading and math tests, respectively, than boys not in the HFZ. Boys in the HFZ for sit-ups were more likely to achieve higher grades on both tests, and those in the HFZ for push-ups were more likely to succeed on the math test.

Rauner et al. (22) utilized 11,743 students from 37 elementary and 10 middle schools in Nebraska. The PACER was used as the measure of aerobic fitness, and subjects were classified as being fit or unfit based on meeting the HFZ 15-lap threshold. Nebraska State Accountability (NeSA) math and reading scaled test scores were used as the dependent variable. Free/reduced lunch status was included in the analysis as a measure of SES. Approximately $70 \%$ of the students were in the PACER HFZ. Following the inclusion of covariates, free/reduced lunch, ethnicity, sex, age, grade-level, 
and school type, aerobic fitness was significantly associated with math and reading test scores. Though SES did not attenuate the association between aerobic fitness and test scores, free/reduced lunch status was significantly correlated with aerobic fitness. Thus, it had an effect on the fitness-academic achievement association. Aerobically fit students not receiving a free/reduced lunch were 2.41 and 2.23 times more likely to pass the math and reading tests, respectively, compared to aerobically unfit students not receiving a free/reduced lunch.

Roberts et al. (24) assessed $7495^{\text {th }}, 7617^{\text {th }}$, and $4799^{\text {th }}$ grade students in their study. FITNESSGRAM data, body weight, and student demographic information was obtained from school records. Aerobic fitness was measured via the mile run test. Students were given a maximum of 15 minutes to walk/run the mile. Failure to do so resulted in students receiving that maximum finish time. California Achievement Tests version 6 (CAT6) math and reading scores and CST math and ELA scores, which are to be completed every year, were used to assess students' academic performance. Parental education level, students' ethnicity, and free/reduced lunch status were self-reported by the parents. $65 \%$ of students were in the non-HFZ for the mile. Students who failed to run the mile in the recommended 15 minutes scored significantly lower on both the CAT6 and CST tests than those in the HFZ. Those not meeting the standards had mean scores of 56.52 and 55.46 on the CAT6 math and reading, respectively, compared to 64.92 and 61.34 for those in the HFZ. Mean scores of 3.52 and 3.44 were achieved on the CST ELA and math tests, respectively, for those who did not meet the aerobic fitness standards compared to scores of 3.85 and 3.81 for those in the HFZ. With aerobic fitness split into quintiles, lower quintiles were associated with lower test scores, establishing a dose- 
response relationship. In full regression models, mile run time was a significant predictor of standardized test scores even though the association was attenuated with the inclusion of confounding variables.

Each of these studies resulted in significant associations between aerobic fitness, as measured by the PACER or mile run, and standardized test achievement in students from different parts of the U.S. These associations remained significant after the inclusion of confounding variables, thus showing aerobic fitness is a strong predictor of achievement. Utilizing FITNESSGRAM assessments to measure aerobic fitness brings about several limitations. These assessments are conducted by physical education teachers, aside from Castelli et al. (4), and it is unknown of they were administered and performed correctly despite receiving prior FITNESSGRAM training. Also, motivation can play a big role in students' performance. It is assumed that all students exerted a maximal effort on each assessment, which may not have been true. In regards to Roberts et al. (24), using a mile-time cut off can overestimate students' aerobic fitness, as some students could have had slower mile times than 15 minutes.

Physical activity as measured by FITNESSGRAM assessments has been consistently associated with academic performance. Specifically, aerobic fitness is the strongest predictor of academic performance. Using age- and sex-specific standards for each assessment makes the results more valid and useful. Though FITNESSGRAM is not an objective measure of overall physical activity, the results of these studies show that fitness levels in youths and adolescents play a significant role in standardized test achievement. 


\section{Physical Education and Academic Performance}

Changes within physical education classes, in regards to intensity and duration of activity, can have positive effects on students' academic performance. A randomized controlled trial increasing the volume and intensity of activity during physical education (PE) classes resulted in increases in school grades. Ardoy et al. (1) conducted the study using 67 adolescents ages 12-14 from Spain. Students were randomized into a control group $(\mathrm{CG})(\mathrm{n}=17)$, which partook in normal PE classes (55 minutes, twice a week), an experimental group $1(\mathrm{EG} 1)(\mathrm{n}=20)$, which partook in 4- 55 minute PE sessions a week, and an experimental group $2(\mathrm{EG} 2)(\mathrm{n}=17)$, which partook in $4-55$ minute PE sessions a week of high intensity activity. High intensity was defined as having a heart rate above $120 \mathrm{bpm}$ and was measured using a Polar-610 heart rate monitor. The intervention took place over a 4 month period. Physical fitness assessments tested aerobic fitness, muscular

fitness, and speed/agility before and after the intervention. Aerobic fitness was assessed via a 20 -meter shuttle run test. Muscular fitness was measured by a standing long jump test. A 4 x 10-meter shuttle run test was used to measure speed and agility. Academic performance was assessed both pre- and post-intervention using student's average school grades.

At baseline, EG1 had significantly lower academic scores compared to the CG and EG2. Baseline measures were adjusted for along with sex, sexual maturation, and attendance. EG2 improved their average academic scores significantly compared to the other two groups $(p<0.001)$. No differences were found in the CG and EG1 after the intervention. There were no associations between changes in the fitness variables and changes in academic performance. 
The results of this study show that increasing the intensity and duration of activity in physical education classes, as opposed to solely duration, has a more profound effect on academic performance. Kwak et al. (15) also found a higher intensity level to be positively associated with academics. This is contrary to the Syvaoja et al. (26) study which found intensity, specifically MVPA, was not associated with GPA. Also, changes in fitness assessment scores were not related to changes in academic performance which was consistent with the findings of the London and Castrechini (18) longitudinal FITNESSGRAM study. Limitations to this study include the small sample size and the randomization of groups, not individuals. This resulted in baseline measurement differences, which were eventually controlled for. Despite these limitations, incorporating additional and higher intensity physical activity into the school day, whether it be in physical education classes or into normal curricula as shown in Reed et al. (23), has beneficial effects on academic performance.

\section{Weight Status and Academic Performance}

Along with researching the benefits of physical activity on academic success, studies have concurrently examined the relationship between weight status, as measured by BMI, and academic performance. Weight status classifications are based on BMI-forage percentiles: normal weight $\left(<85^{\text {th }}\right.$ percentile), overweight $\left(\geq 85^{\text {th }}\right.$ to $<95^{\text {th }}$ percentile), or obese $\left(\geq 95^{\text {th }}\right.$ percentile). In the FITNESSGRAM battery, youth are considered to be in the HFZ if they are of a normal weight. Results from examining the association between weight status and academic performance have been inconsistent.

Castelli et al. (4) and Roberts et al. (24) found an inverse association between BMI and standardized test scores. Castelli et al. (4) conducted their research using $2593^{\text {rd }}$ 
and $5^{\text {th }}$ grade students, whereas $5^{\text {th }}, 7^{\text {th }}$, and $9^{\text {th }}$ grade students were used in Roberts et al. (24). Castelli et al. (4) found BMI to be negatively correlated ( $r=-0.27$ to -0.28$)$ with ISAT math, reading, and total scores $(p<0.001)$. In a full regression model controlling for poverty index, school, sex, age, and each FITNESSGRAM subset, weight status remained significantly associated with math, reading, and total ISAT scores, though the association was attenuated. $31.8 \%$ of boys and $27.7 \%$ of girls were overweight/obese in Roberts et al. (24). Those who were overweight or obese scored significantly lower than those of normal weight on both CAT6 and CST tests. When classified into quintiles, those in the higher BMI-for-age percentile quintiles scored lower on the CAT6 tests as well as the CST math test than those in lower BMI percentiles, thus establishing a doseresponse relationship. As with Castelli et al. (4), the inclusion of age, free/reduced lunch status, and ethnicity weakened the relationship between weight status and test scores, but weight status still remained a significant predictor.

A physical activity intervention study also found weight status to be associated with standardized test scores. Reed et al. (23) used BMI values from $1553^{\text {rd }}$ grade youth that were only measured at baseline. Therefore, effects of the intervention on weight status and changes in the relationship between BMI and academic achievement could not be determined. Subjects were classified as being in the HFZ or non-HFZ. $91 \%(n=73)$ of the subjects in the EG (experimental group) and $75 \%(n=56)$ of subjects in the CG (control group) had BMI values in the HFZ. This difference was not significant. Those in the HFZ received a greater percentage of "Proficient" and "Advanced" marks on the PACT test. Significant differences were only found for the Social Studies test scores, 
with subjects in the non-HFZ group scoring significantly lower $(F=5.932, \mathrm{df}=1, p=$ 0.017) than those in the HFZ group.

Studies have also found weight status to be initially associated with academic performance, but the inclusion of SES variables attenuated the relationship to be nonsignificant in some instances. Rauner et al. (22) and Van Dusen et al. (27) used BMI data previously collected during FITNESSGRAM assessments. Rauner et al. (22) used BMI percentile as a continuous variable when examining the relationship in $4^{\text {th }}-8^{\text {th }}$ grade students. BMI percentile was a predictor of NeSA math and reading scores until free/reduced lunch status was included into the final model. Van Dusen et al. (27) found similar results in a sample of $3^{\text {rd }}-11^{\text {th }}$ grade students. The strength of BMI as a predictor of TAKS scores weakened with the inclusion of school lunch status and other covariates. In girls, no association was found, and no differences were found between the high and low or moderate BMI quintile. In boys, a lower BMI resulted in lower TAKS scores than in boys with a moderate BMI. This shows that there is no linear association between BMI and academic scores when accounting for confounding variables. Both of these studies showed that SES variables can be a stronger predictor than weight status for academic achievement.

LeBlanc et al. (16) and London and Castrechini (18) both found weight status to have no association with standardized test scores. LeBlanc et al. (16) examined if percent body fat, which was analyzed via a Tanita Body Composition Analyzer (TBF-310), and BMI percentile were predictors of $4^{\text {th }}-6^{\text {th }}$ grade academic performance. BMI percentile and percent body fat were not significantly correlated with test achievement $(r=-0.3$ to 0.3 ). When children were divided into 2 groups based on if they were extremely obese ( $\geq$ 
1.2 times the $95^{\text {th }}$ BMI percentile) or not, there was no difference in academic performance between groups. Similarly when children were classified as being normal weight, overweight, or obese, no group differences were found. These results show that regardless of how weight status is defined, weight status has no association with academic performance. London and Castrechini (18) utilized BMI as measured during FITNESSGRAM assessments in $4^{\text {th }}-9^{\text {th }}$ grade students. Associations with CST scores were examined initially and longitudinally. BMI was not associated with test scores initially nor longitudinally after 2 years. Therefore, changes in BMI may not predict changes in standardized test scores.

The inconsistencies in results pertaining to the association of weight status and academic performance in youths and adolescents disallows conclusions from being made. As with the physical activity and academic performance relationship, more research is needed in order to establish more definitive results in youth.

Physical Activity, Weight Status, and School Behavior

The effects of physical activity and weight status on in-class behavior, including time-on-task behavior, attentiveness, and interruptive behavior, have been researched previously (with the exception of the physical activity-interruptive behavior relationship). In-class behaviors can influence students' academic performance. Examining the relationship between physical activity, weight status, and classroom behaviors can add to the potential benefits of the latter variables on overall academic performance. These associations have yielded inconsistent results.

Most studies have utilized physical activity interventions to assess the effects of physical activity on students' abilities to stay on task. Mahar et al. (19) found $3^{\text {rd }}-4^{\text {th }}$ 
grade students' $(n=62)$ time-on-task increased following an in-class physical activity intervention. 2 out of the 3 classes from each grade level were randomly assigned as the intervention groups while each remaining class served as the control group. The intervention group had 10 minutes of physical activity incorporated into their class every day for 12 weeks. Teachers received prior training in order to correctly administer active lessons. The control group received the normal academic curricula. Students in each class randomly wore Yamax SW-200 pedometers for 5 days out of the 12 weeks to assess physical activity during the school day. Steps were recorded after the completion of the incorporated physical activity and at the end of the school day for both groups. On-task behavior was observed by two trained observers in each class 30 minutes prior to activity and 30 minutes following activity. 6 different students were observed each day in 5- 1 minute intervals. Observers recorded after each minute describing the students' on-task behavior or lack thereof. On-task behavior was defined as motor or verbal behavior pertaining to the class lesson. Teachers and students were unaware of who was being observed each day.

The intervention group took significantly more steps per day (782 steps) than the control group. The number of steps the intervention group took during the 10 minutes of physical activity ranged from 160 to 1223 steps. Post-activity on-task behavior significantly increased by $8 \%$ compared to pre-activity behavior. This increase had a moderate effect size of 0.60 . Students who were the least on-task experienced the greatest increases in on-task behavior following the intervention. Following physical activity, ontask behavior of these students significantly increased by $20 \%$. 
This study shows a short bout of physical activity increases on-task behavior acutely in the classroom. A limitation of this study is that the observers were not blinded. In using 2 observers per classroom, the researchers were confident that the observers were unbiased as they had an agreement of $94 \%$ for on-task behavior. Also, this study shows the acute effects of physical activity, and it is unknown if habitual physical activity can increase on-task behavior.

Similar to the previous study, Grieco et al. (12) incorporated physical activity into 9- $3^{\text {rd }}$ grade classrooms $(n=97)$ to determine the effects on on-task behavior. Students completed both an active and inactive control lesson. The active lesson consisted of 1015 minutes of MVPA as conducted by the teachers who received prior training. Curriculum for the active and inactive lessons were the same throughout each classroom. Active lessons were to be incorporated at least 4 days a week throughout the school year. Students wore Omron HJ 105 pedometers to measure steps taken during the school day for a week. On-task behavior was observed by 2 researchers. Students were observed for 15 minutes before and after each active/inactive lesson. Each student was observed for 5 seconds before the researcher moved onto the next student. Researchers observed each student 16 to 22 times per 15 minute period. Observers were blinded, and the order of the lessons were randomized. On-task behavior was defined as paying attention to the teacher or actively engaging in the teacher assigned task. Off-task behavior was characterized by the student staring off, placing their head on the desk, talking or looking at other students, drawing, etc. BMI was also measured to determine if weight status was associated with on-task behavior. Children were classified as underweight, normal weight, overweight, or obese based on their BMI-for-age percentile. 
$37 \%$ of children were overweight or obese. BMI had an inverse association with steps taken per day. Across all BMI categories, time-on-task significantly decreased from before to after the inactive lesson. Increases in BMI were associated with decreases in ontask behavior following the inactive lesson. On-task behavior slightly increased following the active lesson, but the difference was non-significant. Weight status also had no association with time-on-task following physical activity.

Incorporating MVPA into the classroom did not significantly increase time-ontask. These results also show that BMI moderates the effect of physical activity on ontask behavior. As with the previous study, these are measurements of the acute effects of physical activity. Though habitual physical activity was measured, it was not examined in the statistical analyses in order to determine the association with on-task behavior.

The effects of physical activity and weight status on classroom attention in youth has been previously shown to elicit inconsistent results as well. Physical activity intervention studies have been commonly used in assessing the relationship between physical activity and attention. Pellegrini et al. (21) examined the effect of recess on attention in $2^{\text {nd }}(n=24)$ and $4^{\text {th }}(n=21)$ grade children. Children received 30 minutes of recess, 4 days a week. Physical activity during recess was assessed via a 9-point scale system to code how active the children were with 1 being lying down/no movement and 9 being running across the playground. Prior to and following recess, teachers read to the students. 20 minute observations conducted by 4 trained observers occurred each day for 2 months during pre- and post-recess. Each student was observed in 30 second intervals and for an average of 21 times during each observation period. Inattention was coded during each observation and was defined as not looking at the teacher during the lesson. 
$2^{\text {nd }}$ grade students were less attentive than $4^{\text {th }}$ grade students prior to recess. $4^{\text {th }}$ grade children were more active than $2^{\text {nd }}$ grade children during recess. Also, boys were more active than girls. Recess physical activity was not correlated with post-recess attention. However, task inattention was significantly greater prior to recess than after in each grade. These results support that physical activity during the school day can increase in-class attention specifically in grade-school children.

Conversely, integrated physical activity has also been found to have no effect on attention. Davis et al. (10) used after-school exercise interventions to examine the effects on overweight children's attention. The subjects had no medical conditions, such as attention-deficit disorder, nor were taking medications that could have influenced results. Children were split into a control group $(\mathrm{n}=29)$, low-dose exercise group $(\mathrm{n}=33)$, which received 20 minutes of physical activity, and a high-dose exercise group $(\mathrm{n}=32)$ receiving 40 minutes of activity. The intensity of the physical activity, which included running games, sport games, and jump rope, in each experimental group was consistent at a heart rate greater than $150 \mathrm{bpm}$. The intervention occurred 5 days a week for 15 weeks and was instructed by researchers and exercise science college majors. Children's cognitive performance was assessed at baseline and following the intervention via the Cognitive Assessment System (CAS), which is a standardized test measuring planning, attention, simultaneous, and successive cognitive processes. The attention portion of the test required children to focus on the cognitive activity and resist distraction. The test was administered by a blinded psychologist.

No significant group differences were found on the CAS Attention test. Regardless of the duration, physical activity had no effect on overweight children's 
attention. Using a standardized measurement of attention helps to strengthen the results

of the study, but it is unknown how these results would translate into the classroom. Also, the study was conducted using only overweight children, and therefore can only be generalized to that population.

Weight status was found to be predictive of attention in a study conducted by Datar et al. (9). Data from the Early Childhood Longitudinal Study was used to analyze changes in weight status and in-class behaviors from kindergarten to $3^{\text {rd }}$ grade in approximately 7,000 children. The Early Childhood Longitudinal Study contains nationally representative date of children in the U.S. Children were classified as never obese, became obese, and always obese based on their weight status changes throughout the observational period. In-class behavior was assessed by the teachers using a social rating scale. This scale contained measurements of externalizing behavior problems (arguing, fighting, disturbs activities etc.), internalizing behavior problems (anxiety, loneliness, low self-esteem), approaches to learning (attentiveness, learning independence, organization), self-control (controlling temper, respecting others), and interpersonal skills (forming and maintaining friendships, helping others, empathy). Teachers reported how often the children demonstrated each behavior on a scale of 1 to 4 with 1 being never and 4 being most of the time.

From baseline to $3^{\text {rd }}$ grade, the prevalence of obesity increased from $9 \%$ to $17 \%$. A regression analysis controlling for confounders including mother's education level and familial income and split by gender revealed that girls who became obese were significantly more likely to have lower scores for approaches to learning compared to girls who were never obese. Girls who were always obese were not statistically different 
from those who were never obese in regards to approaches to learning. In boys, there was no association between change in overweight status and approaches to learning.

Changes in weight status were associated with changes in approaches to learning, which included a measurement of attention, in girls. Since approaches to learning was comprised of other learning variables, it is unknown if solely attention was related to changes in weight status. Also, school behavior was teacher-reported. There is potential for bias or misinterpretations of behavior since they are not trained in behavior analysis. Different teachers may have different definitions for inattention.

Judge et al. (14) utilized data from the Early Childhood Longitudinal Study to determine the association between weight status and attention in $13,6803^{\text {rd }}$ grade students using a cross-sectional design. Children were classified based on obesity (obese or not obese). Measurements of classroom behavior were the same as in the previous study. $16.2 \%$ of children were obese with a higher prevalence in boys (16.4\%) than girls (15.9\%). Obese girls had lower mean scores for approaches to learning than non-obese girls. When controlling for SES, maternal education level and race, there was no difference in approaches to learning between the two groups. In boys, weight status was not associated with approaches to learning. Though this study and the previous study used near identical methodologies and utilized the subjects from the same database, the results differed in girls. Changes in weight status may be associated with changes in approaches to learning, but when examined cross-sectionally, no difference exists based on obesity status.

The relationships between physical activity, weight status, and interruptive behavior have been less researched. Datar et al. (9) and Judge et al. (14) examined the 
relationship between weight status and externalized behavior problems, which included a measure of disruptive behaviors, in grade-school children in the previously discussed studies. As mentioned previously, Datar et al. (9) examined how changes in weight status effected externalized behavior problems. Externalized behavior problems in the classroom were significantly more frequent at baseline in children who were always obese compared to those who were never obese or became obese during the observational period. There were no group differences at the end of the study period. Girls who became obese were more likely to exhibit externalized behavior than girls who were never obese. However, there were no differences between girls who were always obese and never obese. For boys, becoming obese or always being obese was associated with significantly less externalized behavior problems compared to those who were never obese. Judge et al. (14) found obese girls to have higher mean externalized behavior scores compared to non-obese girls, with no difference in boys. Similarly, obese girls were more likely to exhibit external behavior problems than non-obese girls. As with the approaches to learning in these studies, externalized behavior problems encompassed other variables along with disruptive behavior. Therefore, conclusions cannot be made regarding the relationship between weight status and interruptive behavior.

The relationship between physical activity, weight status, and school behavior remains unclear due to the inconsistency of results, varying methodologies, and differing definitions of on-task behavior, attentiveness, and interruptive behavior. The effects of physical activity were also only shown acutely as a result of interventions. The effect of habitual physical activity on school behavior was not examined. 


\section{Conclusion}

Due to the inconsistencies in the associations between physical activity, weight status, and academic performance as a whole, future research is needed. Research should focus on using objective measures of habitual physical activity to get a better representation of youths daily physical activity levels. Defining academic achievement in terms of school grades as opposed to standardized test scores would be more reflective of students' intelligence. School behavior variables should be measured by trained observers in the classroom, and variables should have more definitive definitions. Finally, the relationship between habitual physical activity and school behavior should be examined to determine if active children are more attentive, stay on task, and less disruptive in the classroom. 


\section{CHAPTER II}

INTRODUCTION

It is estimated that $22-39 \%$ of U.S. youth are sufficiently active according to current physical activity recommendations (6) and youth are sedentary an average of 6 $\mathrm{hr} / \mathrm{day}^{-1}(20)$. Along with these inactivity inclinations, the prevalence of overweight and obese youth has increased in recent years. The 2011-2012 National Health and Nutrition Examination Survey (NHANES) estimated that $31.8 \%$ of children and adolescents ages 2-19 are overweight or obese (5). This frequency has increased from 30\% in 2005-2006 and $28.1 \%$ in $1999-2000$. These increases are due to the rising prevalence of obesity (13.9\% in $1999-2000,15.4 \%$ in $2005-2006$, and $16.9 \%$ in $2011-2012)$ rather than overweight. The prevalence of overweight/obesity increases with age (5) and tracks into adulthood. In a sample of 854 U.S. children, approximately $80 \%$ of overweight adolescents were obese in young adulthood (21-29 years of age) (28). Obesity in childhood can also lead to chronic diseases in adulthood, such as metabolic syndrome (25) and coronary heart disease (2). To add to these problems, opportunities for physical activity are being removed within schools; where $4 \%$ of elementary schools, $8 \%$ of middle schools, and 2\% of high schools provided daily physical education in 2006 (17).

Regular physical activity is a preventive measure in youth to decrease the risk of obesity and other chronic diseases. Along with the many health benefits of physical 
activity, cognitive benefits have been examined as well. Physical activity has been linked to increased cerebral blood flow, increased cognitive function, and better mood states $(8,13)$. Specifically, exercise has been shown to increase and regulate brain-derived neurotrophic factor (BDNF), which enhances learning and cognition (8). Physical activity has also been shown to elicit structural changes in the hippocampus, which plays an important role in memory (7). With physical activity integrated into the classroom, children performed significantly better on a test measuring general intelligence and cognitive ability than those not receiving physical activity (23).

With the cognitive benefits of physical activity and increased prevalence of obesity in children, research has been conducted examining the potential benefits of physical activity on academic performance in children and adolescents. Mixed results have been found utilizing different methodologies. Aerobic fitness, as measured by FITNESSGRAM assessments, has been found to be associated with better standardized test scores $(3,4,18,22,24,27)$ in $3^{\text {rd }}-11^{\text {th }}$ grade students. In measuring physical activity objectively, one study found vigorous physical activity was associated with better grades in girls ages 9-10 and 15-16 but not boys (15), and another found no relationship between moderate-vigorous physical activity (MVPA) and content test scores (16). In experimental research, integrated physical activity during class time resulted in increased standardized scores (23). Additionally, in examining the link between physical activity and academic achievement, dose-response relationships have been observed. A doseresponse relationship was found for intensity and duration of activity and better school grades in a randomized controlled trial utilizing $7^{\text {th }}-9^{\text {th }}$ grade adolescents (1) and for cardiovascular fitness and test scores (27). However, in using objective measurements of 
physical activity, time spent in MVPA nor sedentary time were associated with grade point average (GPA) (23) or standardized test achievement (16).

Along with researching the benefits of physical activity on academic success, studies have concurrently examined the relationship between weight status, as measured by body mass index (BMI), and academic achievement. As with physical activity, BMI results have been inconsistent. In $3^{\text {rd }}-5^{\text {th }}$ grade children, BMI was found to have an inverse relationship with standardized test scores (4). A nonlinear BMI relationship was found in $3^{\text {rd }}-11^{\text {th }}$ grade children and adolescents. Those with a lower BMI had a lower mean standardized test score than those with a moderate BMI but not a high BMI (27). Many studies have found no relationship between weight status and academic performance. Neither BMI percentile nor adiposity were associated with greater test scores in $4^{\text {th }}-6^{\text {th }}$ grade children (16). Weight status, as defined by being in the FITNESSGRAM healthy fitness zone, was not associated with adolescents' school grades (22). One study found no initial or longitudinal relationship with academic performance (18). One of these studies found BMI to have an association with test scores, but the finding was attenuated with the inclusion of confounders, including fitness level (24).

The associations of physical activity and weight status with in-class behavior of elementary school students have also been previously researched. Most studies have utilized physical activity interventions to examine effects on student's abilities to stay on task and on attention. Following physical activity, on-task behavior was better than that prior to activity in $3^{\text {rd }}-4^{\text {th }}$ grade students (19). In regards to weight status, time spent ontask and BMI status had an inverse association following a normal, inactive teaching 
lesson (12). However, there was no change in time-on-task following MVPA for either weight status (12). Inconsistent results were also found when the effects of physical activity on attention were examined. In $2^{\text {nd }}-4^{\text {th }}$ grade students, in-class attention increased following a recess period (21). Conversely, incorporating vigorous physical activity outside of school had no effect on attentiveness, as measured objectively via a standardized assessment, in grade-school children (10). In examining the relationship between weight status and attention, overweight girls displayed mixed results of being less attentive (9) and no different (14) than normal weight girls.

Associations with disruptive in-class behavior in youth without clinical disabilities has been less researched than the previous behaviors. Studies involving physical activity have not been found. Weight status and external behavior problems, including disruptive behavior, have established a positive relationship. Overweight Kindergarten and $3^{\text {rd }}$ grade children have been found to display more disruptive behavior than children of a normal weight status (9). Gender differences have been exhibited as overweight girls are more disruptive than normal weight girls in the classroom with no differences in boys $(9,14)$.

Past studies have not examined the relationship between meeting physical activity recommendations, as defined by step counts per day ( $\geq 12,000$ steps/day), with teacherreported grades. The relationship between habitual physical activity, weight status, and classroom behaviors that can have an impact on academic achievement is scarcely researched without the inclusion of physical activity interventions. With including school behavior variables, "academic performance" will be more encompassing, and potential benefits of physical activity with academic performance can be expanded upon. In 
addition, socioeconomic status has been found to be correlated with academic achievement and can present a barrier in examining the associations between physical activity, weight status, and academic performance. The influences of socioeconomic status, as defined by parental education level, has been less researched with classroom behavior and thus overall academic performance.

\section{Purpose}

This study aims to uncover the association between physical activity, weight status, and overall academic performance, including academic grades and in-class behavior, with the inclusion of parental education level. It is hypothesized that those meeting physical activity recommendations and those of normal weight will have greater academic performance regardless of the potential influences of parental education level. 


\section{CHAPTER III METHODOLOGY}

\section{Participants}

Participants of the study were from an a childhood obesity intervention known as SWITCH, a family, community, and school based intervention targeting childhood obesity completed in the fall of 2005. Ten elementary schools from two Midwestern school districts in Lakeville, Minnesota and Cedar Rapids, Iowa participated (4 in Lakeville and 6 in Cedar Rapids). Cross sectional data was used for the current analysis, which was collected prior to the formation of treatment and control groups in 2005. Prior to data collection, written consent and assent was obtained from each guardian and child, respectively, as risks and study procedures were explained both verbally and in writing. Consent was provided by the teachers to complete the teacher surveys. The study procedures were approved by the University of Minnesota's Human Subjects Review Board.

Of the 2113 students enrolled in the two school districts, $1,4303^{\text {rd }}-5^{\text {th }}$ grade students chose to participate in the intervention. 614 children (53.9\% female, age $9.6 \pm$ 0.9 years) met the inclusion criteria and were included in the final analytical sample (Table 1). Participants were excluded for missing data on physical activity, body mass index, teacher grade, school behavior, or socioeconomic status. However, the 
demographics of the final sample are similar to those of the two school districts in which the participants attended.

Table 1. Sample Descriptive Statistics

\begin{tabular}{lccc}
\hline & $\begin{array}{c}\text { Total } \\
(\mathbf{n = 6 1 4})\end{array}$ & $\begin{array}{c}\text { Boys } \\
(\mathbf{n = 2 8 3})\end{array}$ & $\begin{array}{c}\text { Girls } \\
(\mathbf{n = 3 3 1})\end{array}$ \\
\hline Age $($ years $)$ & $9.6(0.9)$ & $9.6(0.9)$ & $9.6(0.9)$ \\
Height $(\mathrm{cm})$ & $138.4(7.5)$ & $139.1(7.0)$ & $137.9(7.9)$ \\
Weight $(\mathrm{kg})$ & $35.6(9.3)$ & $36.5(8.8)$ & $35.3(9.7)$ \\
Body mass index $\left(\mathrm{kg} / \mathrm{m}^{2}\right)$ & $18.4(3.5)$ & $18.5(3.4)$ & $18.3(3.6)$ \\
BMI Percentile & $62.0(28.2)$ & $64.7(26.9)$ & $59.6(29.1)$ \\
Average steps/day & $11,786(3,100)$ & $12,785(3,409)$ & $10,933(2,516)$ \\
\hline
\end{tabular}

Values expressed as mean (standard deviation)

\section{Anthropometry}

Anthropometric measurements were taken by a school nurse following standard procedures. The nurses were trained prior to data collection. Standing height was taken via a portable stadiometer (Seca Road Rod; Seca, Hamburg, Germany). Body mass was measured via a strain gauge scale (Lifesource MD; Lifesource, Milpitas, CA, USA). Body mass index (BMI, $\mathrm{kg} / \mathrm{m}^{2}$ ) was calculated from standing height and body mass measurements. Individual BMI z-score and percentile were determined using age- and sex-specific growth charts from the Centers for Disease Control and Prevention (11). Children were classified by weight status based on BMI percentiles: normal weight $(<$ $85^{\text {th }}$ percentile), overweight $\left(\geq 85^{\text {th }}\right.$ to $<95^{\text {th }}$ percentile), or obese $\left(\geq 95^{\text {th }}\right.$ percentile).

Physical Activity

Habitual physical activity was assessed via a pedometer (Digiwalker SW-2000). The subjects were instructed to wear the pedometer on the hip during all waking hours. Pedometer accuracy was checked before each data collection period using the shaker test 
and the 10-step test. The shaker test involves shaking the pedometer in a vertical motion ten times and checking the step count recorded. The 10-step test involves the subject walking ten steps and checking the step count recorded by the pedometer. Pedometers that were inaccurate or did not work properly were replaced. Participants recorded the number of steps accumulated each day over 7 consecutive days. Pedometer data was included in the statistical analysis if the participants wore the pedometer for $\geq 4$ days (including at least one weekend day) and $\geq 10$ hours per day. Participants were categorized as meeting or not meeting the physical activity recommendation of $\geq 12,000$ steps per day.

\section{Academic Performance}

Academic performance was measured by a SWITCH baseline survey, consisting of 28 items, completed by the participants' teachers. One survey was completed for each student in the teachers' class. Teachers provided an estimate of each participants' average school grade on a scale of $\mathrm{A}+$ through $\mathrm{F}$. Children were categorized into the following performance groups based on their grade approximation: high ( $\mathrm{A}+$ to $\mathrm{A} ; \geq 97-93 \%$ ) or moderate/low (A- to $\mathrm{F} ; \leq 92 \%$ ). The categories were defined as such to ensure a more equal distribution into each group. The children's inability to stay on task, inattentiveness, and interruption of other children's work was rated on a scale of 1-5 with 1 corresponding to "never true" and 5 corresponding to "almost always true." Participants were grouped by whether the statement was true (score of 2-5; has difficulty staying on task, inattentive, interrupts other) or never true (score of 1) for the statistical analysis of each variable. 


\section{Socioeconomic Status}

Parental socioeconomic status has been associated with children's academic performance. Socioeconomic status was defined by self-reported parental education level. Participants were categorized by whether their parent or guardian attended high school, attended some college, obtained a 2-year degree, obtained a 4-year degree, or completed a graduate/professional degree.

\section{Statistical Analysis}

All statistical analyses were conducted using SPSS version 20.0 (Chicago, IL, USA). Frequency distributions were calculated for meeting physical activity recommendations, weight status, school behavior variables, and parental education level. Univariate logistic regression models, controlling for gender, were conducted to determine the influence of meeting physical activity recommendations, weight status, or parental education level independently on academic performance. Full models, including physical activity, weight status, and parental education level concurrently, were used to further examine the associations with academic performance controlling for and split by gender. Finally, full models, controlling for gender and stratified by gender, were used to determine the associations between each predictor variable and children's inability to stay on task, inability to pay attention, and tendency to interrupt other children's work. A value of $p \leq 0.05$ was used to determine statistical significance. 


\section{CHAPTER IV}

\section{RESULTS}

Approximately 1 in 3 children were overweight or obese (29.6\%) (Table 2).

Nearly half (44.6\%) of the subjects met physical activity recommendations by averaging

Table 2. Descriptive Frequencies

\begin{tabular}{|c|c|c|c|c|c|c|}
\hline & \multicolumn{2}{|r|}{ All } & \multicolumn{2}{|c|}{ Boys } & \multicolumn{2}{|c|}{ Girls } \\
\hline & $\mathbf{n}$ & $\%$ & n & $\%$ & n & $\%$ \\
\hline \multicolumn{7}{|l|}{ Physical Activity Group } \\
\hline$\geq 12,000$ steps/day & 274 & $44.6 \%$ & 163 & $57.6 \%$ & 111 & $33.5 \%$ \\
\hline$<12,000$ steps/day & 340 & $55.4 \%$ & 120 & $42.4 \%$ & 220 & $66.5 \%$ \\
\hline \multicolumn{7}{|l|}{ Weight Status } \\
\hline Normal weight & 432 & $70.4 \%$ & 192 & $67.8 \%$ & 240 & $72.5 \%$ \\
\hline Overweight & 103 & $16.8 \%$ & 54 & $19.1 \%$ & 49 & $14.8 \%$ \\
\hline Obese & 79 & $12.9 \%$ & 37 & $13.1 \%$ & 42 & $12.7 \%$ \\
\hline \multicolumn{7}{|l|}{ Parental Education Level } \\
\hline Graduate/professional degree & 98 & $15.5 \%$ & 40 & $14.1 \%$ & 55 & $16.6 \%$ \\
\hline 4-year degree & 257 & $41.9 \%$ & 119 & $42.0 \%$ & 138 & $41.7 \%$ \\
\hline 2-year degree & 91 & $14.8 \%$ & 47 & $16.6 \%$ & 44 & $13.3 \%$ \\
\hline Some college & 113 & $18.4 \%$ & 55 & $19.4 \%$ & 58 & $17.5 \%$ \\
\hline$\leq$ high school & 58 & $9.4 \%$ & 22 & $7.8 \%$ & 36 & $10.9 \%$ \\
\hline \multicolumn{7}{|l|}{ Staying on Task } \\
\hline No Difficulty & 273 & $44.5 \%$ & 99 & $35.0 \%$ & 174 & $52.7 \%$ \\
\hline Has Difficulty & 340 & $55.5 \%$ & 184 & $65.0 \%$ & 156 & $47.3 \%$ \\
\hline \multicolumn{7}{|l|}{ Paying Attention } \\
\hline No Difficulty & 282 & $46.0 \%$ & 101 & $35.7 \%$ & 181 & $54.8 \%$ \\
\hline Has Difficulty & 331 & $54.0 \%$ & 182 & $64.3 \%$ & 149 & $45.2 \%$ \\
\hline \multicolumn{7}{|l|}{ Interrupts Other's Work } \\
\hline Never True & 339 & $55.3 \%$ & 134 & $47.3 \%$ & 205 & $62.1 \%$ \\
\hline True & 274 & $44.7 \%$ & 149 & $52.7 \%$ & 125 & $37.9 \%$ \\
\hline
\end{tabular}


$\geq 12,000$ steps per day. Boys were more physically active than girls in regard to meeting physical activity recommendations, $57.6 \%$ and $33.5 \%$, respectively. A majority of the subjects had parents who received at least a 2-year college degree (72.2\%). School behavior variables had comparable distributions, where nearly half of subjects had no difficulty staying on task (44.5\%), paying attention (46.0\%), and did not interrupt others (55.3\%). Differences were seen between genders for each school behavior variable. More than half of girls had no difficulty staying on task (52.7\%), paying attention (54.8\%), and did not interrupt others (62.1\%) compared to $35.0 \%, 35.7 \%$, and $47.3 \%$, respectively, for boys.

Subjects meeting and not meeting physical activity recommendations had comparable distributions into the high academic performance group, $33.6 \%$ and $33.2 \%$, respectively (Figure 1). Classifying subjects by weight status followed a similar trend as

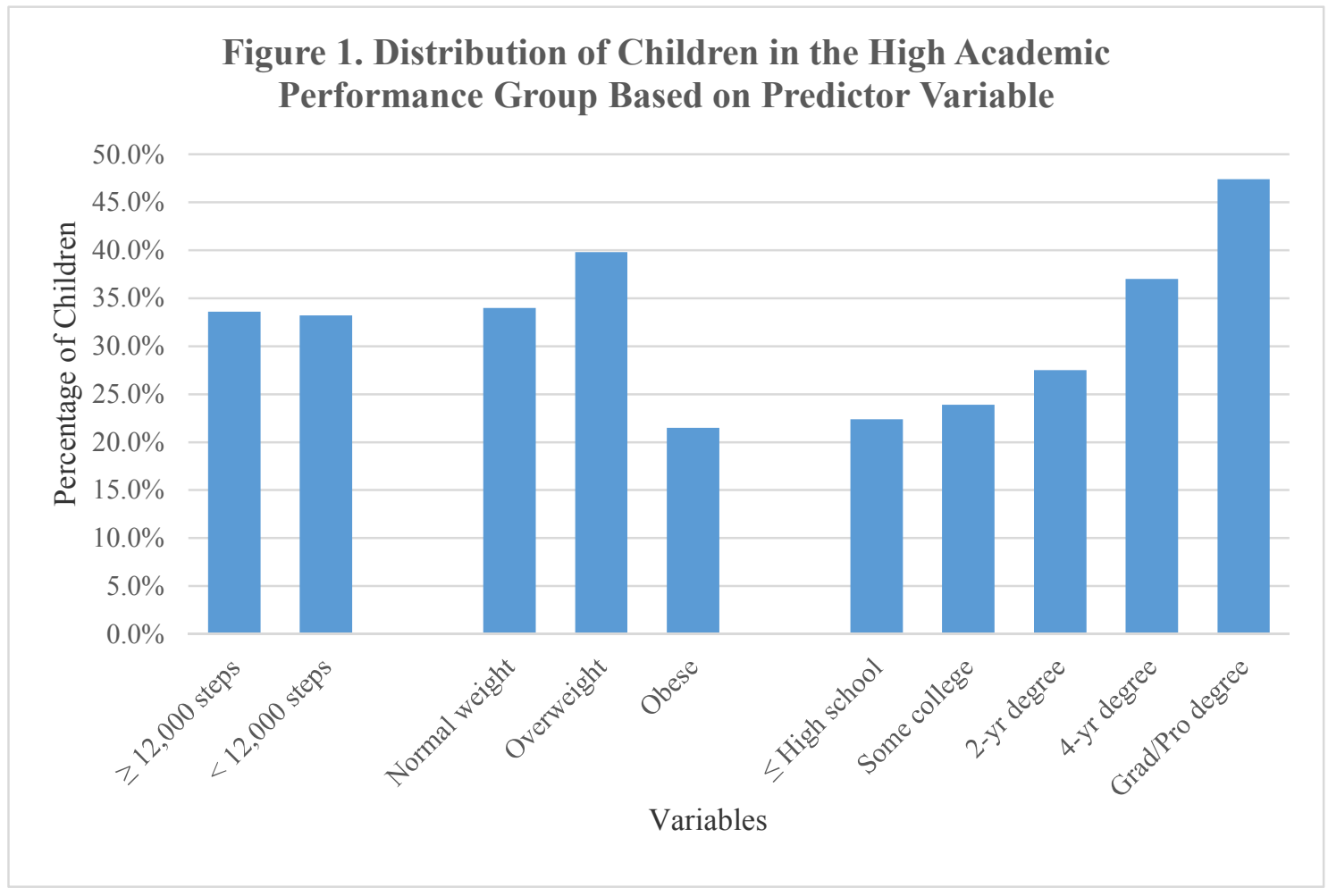


$34.0 \%$ and $39.8 \%$ of normal and overweight subjects, respectively, had high performing grades. High academic performance frequency decreased with obesity to roughly 1 in 5 subjects $(21.5 \%)$. The number of subjects in the high performance group increased with parental education level. Approximately half of the children whose parents received a graduate or professional degree were in the high performance group (47.4\%) compared to $22.4 \%$ of those whose parents completed high school at most. Nearly half (41.6-50.0\%) of the subjects who met physical activity recommendations had no difficulty staying on task, paying attention and did not disrupt others (Figure 2). $45.2 \%, 47.3 \%$ and $55.5 \%$ of normal weight children had no difficulty staying on task, paying attention, and did not interrupt others, respectively, compared to $36.7 \%, 35.4 \%$, and $50.6 \%$ of obese children, respectively. Similarly, as parental education level increased, as did the amount of children having better school behavior. $34.5 \%-41.4 \%$ of children with parents who

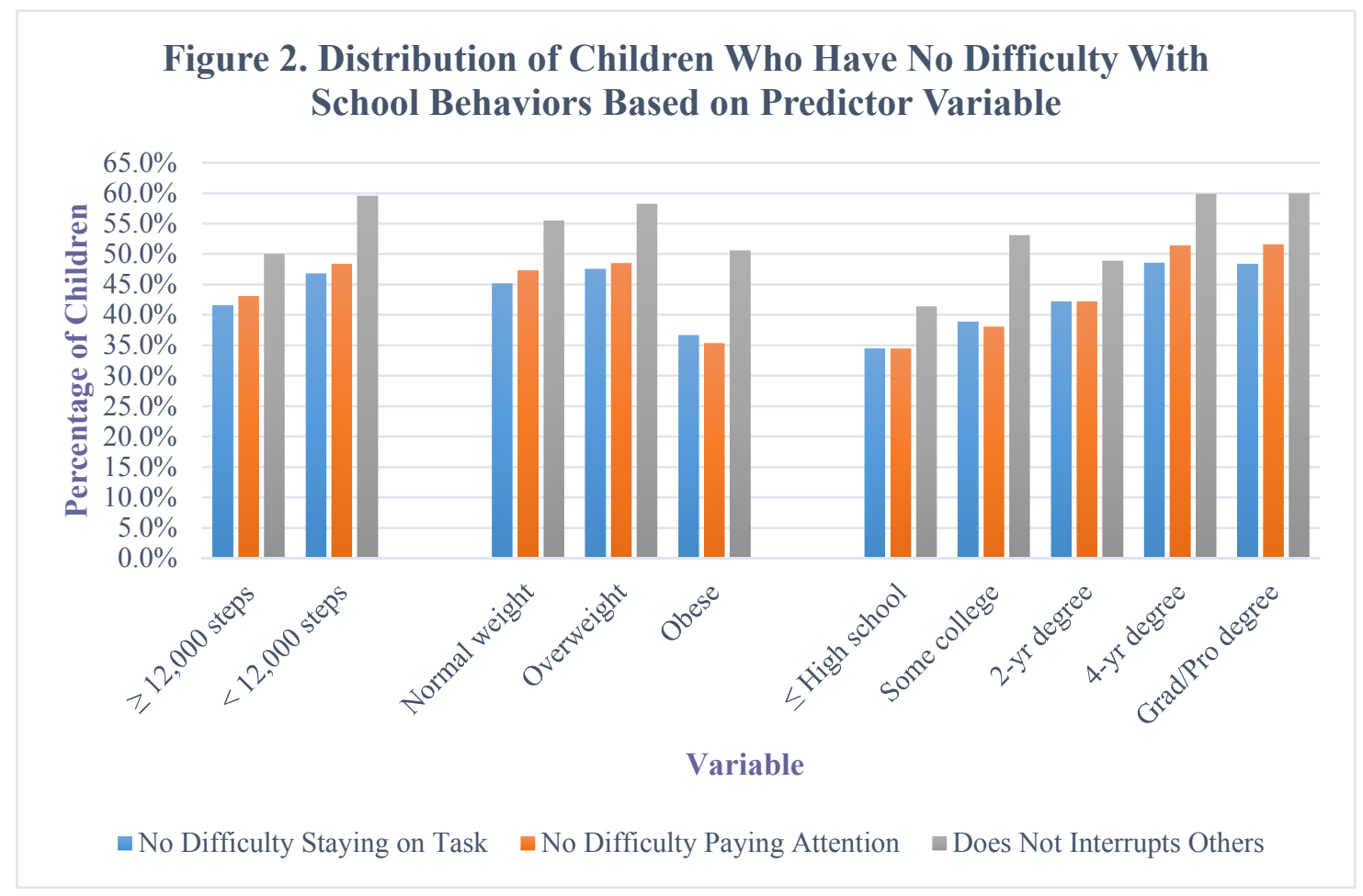


attended high school had no difficulty with their behaviors compared to $48.4 \%-60.0 \%$ of those with parents who attained a graduate or professional degree.

The crude logistic model revealed that obesity was predictive of being in the moderate/low academic performance group, odds ratio (OR [95\% CI]) $1.88(1.1-3.3)$, whereas meeting physical activity recommendations was not predictive, $\mathrm{OR}=1.0(0.7$ 1.4). Parental education level was a stronger predictor, where those with parents that attended high school, some college, or obtained a two-year college degree being more likely to be in the moderate/low academic performance group, OR = 3.1 (1.5-6.5), 2.9 (1.6-5.2), and 2.4 (1.3-4.4), respectively. In the full model, including weight status, physical activity, and parental education level, the latter attenuated the impact of obesity to be insignificant (Table 3). Parental education level remained a significant predictor,

Table 3. Full Logistic Regression Model of Physical Activity, Weight Status, and Moderate/Low Academic Performance Defined by Teacher Grade

\begin{tabular}{|c|c|c|c|}
\hline & $\begin{array}{c}\text { All } \\
(\mathrm{n}=614) \\
\text { OR }(95 \% \mathrm{CI}) \\
\end{array}$ & $\begin{array}{c}\text { Boys } \\
(n=283) \\
\text { OR }(95 \% \text { CI }) \\
\end{array}$ & $\begin{array}{c}\text { Girls } \\
(\mathrm{n}=331) \\
\text { OR }(\mathbf{9 5 \%} \mathrm{CI}) \\
\end{array}$ \\
\hline $\begin{array}{l}\text { Physical Activity Group } \\
\geq 12,000 \text { steps/day } \\
<12,000 \text { steps/day }\end{array}$ & $\begin{array}{c}1.0 \\
1.0(0.7,1.4)\end{array}$ & $\begin{array}{c}1.0 \\
1.4(0.8,2.3)\end{array}$ & $\begin{array}{c}1.0 \\
0.8(0.5,1.4)\end{array}$ \\
\hline $\begin{array}{l}\text { Weight Status } \\
\text { Normal weight } \\
\text { Overweight } \\
\text { Obese }\end{array}$ & $\begin{array}{c}1.0 \\
0.7(0.5,1.1) \\
1.6(0.9,2.8)\end{array}$ & $\begin{array}{c}1.0 \\
0.7(0.4,1.4) \\
0.9(0.4,2.1)\end{array}$ & $\begin{array}{c}1.0 \\
0.7(0.4,1.3) \\
2.4(1.1,5.6)^{*}\end{array}$ \\
\hline $\begin{array}{c}\text { Parental Education Level } \\
\text { Graduate/professional degree } \\
\text { 4-year degree } \\
\text { 2-year degree } \\
\text { Some college } \\
\leq \text { high school }\end{array}$ & $\begin{array}{c}1.0 \\
1.5(0.9,2.5) \\
2.3(1.2,4.3)^{*} \\
2.8(1.5,5.0)^{*} \\
3.0(1.4,6.2)^{*}\end{array}$ & $\begin{array}{c}1.0 \\
1.4(0.7,2.9) \\
2.2(0.9,5.4) \\
3.7(1.5,9.6)^{*} \\
8.7(1.8,43.0)^{*}\end{array}$ & $\begin{array}{c}1.0 \\
1.6(0.8,3.0) \\
2.4(1.1,5.7)^{*} \\
2.2(1.1,4.9)^{*} \\
2.0(0.8,4.9)\end{array}$ \\
\hline
\end{tabular}

* indicates statistical significance $(p<0.05)$ 
$\mathrm{OR}=3.0$ (1.4-6.2), 2.8 (1.5-5.0), and 2.3 (1.2-4.3) for those with parents who attended high school, some college, and obtained two-year degree, respectively.

The full model, stratified by gender, revealed obesity was predictive of girls being in the moderate/low performance group, $\mathrm{OR}=2.4(1.1-5.6)$ (Table 3). Parental education level was a significant predictor as well for girls with parents that attended some college or attained a two-year college degree, $\mathrm{OR}=2.2(1.1-4.9)$ and 2.4 (1.1-5.7), respectively. Parental education level was a stronger predictor in boys, where those with parents that attended high school or obtained a two-year degree being more likely to be in the moderate/low performance group, $\mathrm{OR}=8.7(1.8-43.0)$ and $3.7(1.5-9.6)$, respectively. In the full models for each school variable, controlling for gender, significant predictors were only found for the interrupting other children variable (Table 5). Those who did not meet physical activity recommendations were less likely to interrupt other children's work, $\mathrm{OR}=0.7(0.5-0.9)$. However, those with parents who attended high school were more likely to interrupt other children's work, $\mathrm{OR}=2.1(1.1-4.2)$. In the full models, stratified by gender, it was found that boys with parents that attended some high school were more likely to have difficulty staying on task and difficulty paying attention, $\mathrm{OR}=4.6(1.1-18.5)$ and $6.6(1.3-32.9)$, respectively (Table 4). In girls, obesity was predictive of being inattentive, $\mathrm{OR}=2.2(1.1-4.5)$. Not meeting physical activity recommendations was predictive of a decreased tendency for girls to interrupt other children's work, $\mathrm{OR}=0.5(0.3-0.9)$ (Table 5). 
Table 4. Full Logistic Regression Model of Physical Activity, Weight Status, and School Behavior Variables by Gender

\begin{tabular}{|c|c|c|c|c|}
\hline & \multicolumn{2}{|c|}{ Difficulty Staying on Task } & \multicolumn{2}{|c|}{ Difficulty Paying Attention } \\
\hline & $\begin{array}{c}\text { Boys } \\
(n=283) \\
\text { OR (95\% CI }) \\
\end{array}$ & $\begin{array}{c}\text { Girls } \\
(\mathbf{n}=330) \\
\text { OR }(95 \% \text { CI }) \\
\end{array}$ & $\begin{array}{c}\text { Boys } \\
(n=283) \\
\text { OR }(95 \% \text { CI }) \\
\end{array}$ & $\begin{array}{c}\text { Girls } \\
(n=330) \\
\text { OR }(95 \% \text { CI }) \\
\end{array}$ \\
\hline \multicolumn{5}{|l|}{ Physical Activity } \\
\hline \multicolumn{5}{|l|}{ Group } \\
\hline$\geq 12,000$ steps/day & 1.0 & 1.0 & 1.0 & 1.0 \\
\hline$<12,000$ steps/day & $1.1(0.7,1.8)$ & $0.8(0.5,1.3)$ & $1.3(0.8,2.2)$ & $0.7(0.4,1.1)$ \\
\hline \multicolumn{5}{|l|}{ Weight Status } \\
\hline Normal weight & 1.0 & 1.0 & 1.0 & 1.0 \\
\hline Overweight & $0.9(0.4,1.6)$ & $0.7(0.4,1.4)$ & $0.7(0.3,1.3)$ & $1.0(0.5,1.8)$ \\
\hline Obese & $0.8(0.3,1.7)$ & $1.9(0.9,3.7)$ & $0.8(0.3,1.8)$ & $2.2(1.1,4.5)^{*}$ \\
\hline \multicolumn{5}{|l|}{ Parental Education } \\
\hline Grad/pro. degree & 1.0 & 1.0 & 1.0 & 1.0 \\
\hline 4-year degree & $1.0(0.5,2.1)$ & $0.9(0.5,1.8)$ & $0.7(0.3,1.5)$ & $1.2(0.7,2.4)$ \\
\hline 2-year degree & $1.2(0.5,3.0)$ & $1.2(0.5,2.6)$ & $1.1(0.5,2.7)$ & $1.6(0.7,3.6)$ \\
\hline Some college & $1.9(0.8,4.5)$ & $1.1(0.5,2.4)$ & $2.0(0.8,5.0)$ & $1.4(0.7,3.1)$ \\
\hline$\leq$ high school & $4.6(1.1,18.5)^{*}$ & $1.2(0.5,2.9)$ & $6.6(1.3,32.9)^{*}$ & $1.5(0.6,3.5)$ \\
\hline
\end{tabular}

Table 5. Full Logistic Regression Model of Physical Activity, Weight Status, and Tendency to Interrupt Other Children's Work

\begin{tabular}{|c|c|c|c|}
\hline & $\begin{array}{c}\text { All } \\
(n=613) \\
\text { OR }(95 \% \text { CI }) \\
\end{array}$ & $\begin{array}{c}\text { Boys } \\
(\mathrm{n}=\mathbf{2 8 3}) \\
\text { OR }(\mathbf{9 5 \%} \mathrm{CI}) \\
\end{array}$ & $\begin{array}{c}\text { Girls } \\
(n=330) \\
\text { OR }(95 \% \text { CI }) \\
\end{array}$ \\
\hline \multicolumn{4}{|l|}{ Physical Activity Group } \\
\hline$\geq 12,000$ steps/day & 1.0 & 1.0 & 1.0 \\
\hline$<12,000$ steps/day & $0.7(0.5,0.9)^{*}$ & $1.1(0.6,1.7)$ & $0.5(0.3,0.9)^{*}$ \\
\hline \multicolumn{4}{|l|}{ Weight Status } \\
\hline Normal weight & 1.0 & 1.0 & 1.0 \\
\hline Overweight & $0.9(0.6,1.4)$ & $0.7(0.4,1.4)$ & $0.9(0.4,1.7)$ \\
\hline Obese & $1.2(0.7,1.9)$ & $0.6(0.3,1.4)$ & $1.8(0.9,3.5)$ \\
\hline \multicolumn{4}{|l|}{ Parental Education Level } \\
\hline Graduate/professional degree & 1.0 & 1.0 & 1.0 \\
\hline 4-year degree & $1.0(0.6,1.6)$ & $0.9(0.4,1.7)$ & $1.0(0.5,2.0)$ \\
\hline 2-year degree & $1.6(0.9,2.8)$ & $1.5(0.6,3.5)$ & $1.5(0.7,3.5)$ \\
\hline Some college & $1.3(0.8,2.3)$ & $1.4(0.6,3.3)$ & $1.2(0.5,2.6)$ \\
\hline$\leq$ high school & $2.1(1.1,4.2)^{*}$ & $2.5(0.8,7.6)$ & $2.1(0.9,5.2)$ \\
\hline
\end{tabular}

*indicates statistical significance $(p<0.05)$ 


\section{CHAPTER V \\ DISCUSSION}

The goal of the current study was to determine the association between physical activity, weight status, and grade-school performance while accounting for parental education level. Physical activity was not predictive of academic performance, however, obesity resulted in an increased risk for moderate/low performance. However, when accounting for parental education level, neither weight status nor physical activity were predictive of grade-school performance. Participants with parents that reported attending high school, some college, or attained a two-year college degree were 3.0, 2.8, and 2.3 times more likely to have moderate/low grades, respectively, than those with parents of a higher education level. When stratified by gender, a lower parental education level was the only predictor of moderate/low academic performance in boys. Boys with parents who attended high school or some college were 8.7 and 3.7 times more likely to have moderate/low grades, respectively. Parental education level and obesity were equivalent in strength as predictors of performance in girls. Girls were 2.4 times more likely to have moderate/low grades if obese or they had parents reporting a two-year college degree. Similarly, children of parents who attended some college had a 2.2 increase in the odds of lower academic performance. 
Physical activity and parental education level were predictive of children interrupting other's work. Those not meeting physical activity recommendations were $30 \%$ less likely to interrupt others compared to those meeting physical activity recommendations. When stratified by gender, this likelihood was increased to $50 \%$ in girls. An opposite effect was found for those with parents who attended high school as children were 2.1 times more likely to interrupt other children's work than those with parents who attained a graduate or professional degree. Weight status was predictive of girls having difficulty paying attention in class as those who were obese were 2.2 times more likely to be inattentive. In boys, parental education level was the only predictor of school behavior. Boys with parents who attended high school were 4.6 and 6.6 times more likely to have difficulty staying on task and paying attention, respectively.

Similar studies examining the relationship between physical activity, weight status, and academic performance have found comparable results to the current study. LeBlanc et al. (16) and Syväoja et al. (26) used accelerometers to assess physical activity, specifically time spent in MVPA, and GPA or standardized test scores to measure academic achievement in grade school children. LeBlanc et al. (16) used free/reduced lunch status ( $130-185 \%$ below the poverty line), as opposed to parental education level, to quantify socioeconomic status (SES). Both studies found significant correlations between academics and their respective SES variables. However, these associations were weak (0.19-0.28). In controlling for SES, physical activity was found to have no association with GPA nor test scores. BMI percentile was associated with academic achievement, but the inclusion of SES greatly attenuated the relationship. 
Distinctions in the methodology of these studies can support or dispute the relationships found. $84.7 \%$ of the sample in LeBlanc et al. (16) received free/reduced lunch. $79 \%$ of the Syvaoja et al. (26) sample had parents with a tertiary education level. In the current study, $72.2 \%$ of children had parents with at least a two-year college degree. Vast differences in SES led to the same conclusions, thus increasing the generalization of the results. In measuring physical activity, LeBlanc et al. (16) utilized a 3-day measurement period compared to a 7-day period used in Syvaoja et al. (26) and the current study. With a shorter measurement period, it is unclear how representative the physical activity data is of actual activity levels.

Though SES was found to be associated in the current study and previously mentioned studies, inclusion of mother's education level was found to have no association with achievement in neither adolescent boys nor girls after all variables, including physical activity intensity measured via an accelerometer, were included (15). Measurements in adolescents can lead to differences in results than if measuring children as in the current study. Another study found poverty index, measured by lunch status, to be unrelated to test scores (4).

Physical activity was found to have no association with academic performance in other studies as well. In elementary school children, there was a weak, non-significant association between cardiovascular fitness, as measured by FITNESSGRAM, and test scores (27). Several studies have found physical activity to be predictive of academic achievement, one of which utilized an objective measure of physical activity. Kwak et al. (15) found time spent in MVPA in girls was associated with better test scores. High school adolescents were used in this study making the results less comparable to younger 
children's success due to the developmental changes that are ongoing in these age groups. Several studies using the FITNESSGRAM battery have found positive associations between aerobically fit students and higher test scores $(3,4,22,24)$. SES attenuated the relationship but statistical significance remained in Roberts et al. (24). Those in the "healthy fitness zone" for cardiovascular fitness (35.3\%) were less than those meeting physical recommendations in the current study (44.6\%).

In the current study, obesity was associated with low/moderate academic performance only before the inclusion of parental education level. Van Dusen et al. (27) and Rauner et al. (22) also found the relationship between BMI percentile and academic achievement weakened with the inclusion of school lunch status. Due to the lack of homogeneity in these samples, caution should be used in comparing these results. Roberts et al. (24) found the BMI-for-age relationship with standardized test scores was attenuated with the inclusion of free/reduced lunch status but still remained statistically significant in $5^{\text {th }}, 7^{\text {th }}$, and $9^{\text {th }}$ grade students. Age differences between the current study and Roberts et al. (24) lead to a decreased generalization of the inconsistent results.

Physical activity and weight status had no association with children's ability to stay on task. These results have been previously found in experimental studies utilizing physical activity interventions. Grieco et al. (12) randomly incorporated 10-15 minute active academic lessons, involving MVPA, into $3^{\text {rd }}$ grade classrooms. Following the active lesson, children's time-on-task increased from prior to the lesson, but the increase was non-significant. BMI was also found to have no interaction with staying on task. Contrary to these findings and those of the current study, Mahar et al. (19) found a 10 minute physically active academic lesson occurring each day for 12 weeks consistently 
improved elementary school children's on task behavior by $8 \%$ following the lesson. Both of these previous studies examined the acute effects of physical activity on on-task behavior. Comparison of these results to the current study is difficult, since the current study examined the relationship using habitual physical activity with an observational design.

Physical activity was not predictive of children's ability to pay attention in class in the current study. This was similarly found in an intervention study utilizing an objective measure of attention in overweight youth. Cognitive Assessment System (CAS) Attention scale scores were no different between intervention groups receiving 20 or 40 minutes of after-school physical activity 5 days a week and a control group following the 15 week intervention (10). Due to the standardized assessment of attention, it is unknown how these results translate to youth's attention in the classroom. Also, the use of overweight subjects makes these results less comparable to the current study, in which approximately one-third of subjects were overweight or obese. One study did find an opposite effect of physical activity on attention in elementary school children. Pellegrini et al. (21) found $2^{\text {nd }}$ and $4^{\text {th }}$ grade children's inattention was greater prior to 30 minutes of recess than after. Attention in the previous study was defined by the children's gaze during the reading lessons prior to and following recess. Operationalization of students' attention is unknown in the current study.

Obesity was predictive of inattention in girls. Weight status was found to be associated with decreased attention in girls in a previous study as well. In a longitudinal study following children from kindergarten to $3^{\text {rd }}$ grade, girls who were always obese or became obese had a decreased approach to learning than girls who were never obese after 
the inclusion of mother's education level and familial income (9). The measurement of individuals' approach to learning was a combined measure of attention along with other learning variables. Therefore, it is unknown if attention was exclusively related to weight status. A study utilizing the same methodology cross-sectionally in $3^{\text {rd }}$ grade students found girls who were obese had a decreased approach to learning compared to girls of a normal weight status, but mother's education level and familial income attenuated the relationship to be non-significant (14). Both of these previous studies also found that weight status was unrelated to approaches to learning which was similarly found in the current study. Discrepancies in the methodology between the previous studies and the current study make for unclear comparisons and results regarding the relationship between attentiveness and weight status.

Physically active youth were more likely to interrupt other children's work. The likelihood of disrupting others was increased for physically active girls. We were unable to identify any previous research between physical activity and disruptive classroom behavior in youths without a clinical disability. A possible reasoning that physically active children were more disruptive of other children's work is that physical activity improves mood states. Children that are active are more alert and in better moods which can cause them to be more social and possibly interrupt their peers. Some previous studies have found weight status to be predictive of external behavior problems, including interruptive behavior. Obesity was associated with more external behavior problems in kindergarten and $3^{\text {rd }}$ grade students (9). Obese girls were more likely to exhibit external behavior problems in the classroom, after the inclusion of SES variables $(9,14)$. As with the attention measures mentioned previously, external behavior 
encompassed other variable measurements aside from disruptive behavior. Associating interruptive behavior with weight status in these studies is unwarranted.

\section{Limitations}

There were several limitations to this study. One limitation is the unequal distributions into the high and moderate/low performance groups, $33.4 \%$ and $66.6 \%$, respectively. This was due to the defining of high and moderate/low performance. Teachers generally rated students very positively as the teachers estimated that a majority of the students had A grades and approximately $10 \%$ had a $\mathrm{C}$ or lower. The groupings of $\mathrm{A}+$ to $\mathrm{A}$ and $\mathrm{A}-$ to $\mathrm{F}$ were used to create a more equal distribution of participants. Another limitation is the teacher estimation of grades and school behavior. Grades were an approximation of how well they were performing in each class subject and may not be the children's actual overall grade. Also, the sample was fairly attentive and wellbehaved in the classroom as determined by the teachers. This can lead to inconsistencies of how attentiveness, staying on task, and interrupting students are defined. In addition to having a positively rated, well-behaved population, subjects were also more fit in terms of steps per day with nearly half of the children meeting physical activity recommendations. These results may not be applicable to unfit populations. Finally, though an objective measure of physical activity was used, pedometers are limited in the activities they can detect. Pedometers do not account for activities such as bike riding or swimming. Therefore, children's physical activity levels may be underestimated when using steps counts per day. 


\section{CHAPTER VI}

CONCLUSION

Physical activity was not associated with grade-school performance overall, but less active children were less likely to disturb others. For girls, obesity was predictive of low/moderate academic performance and a tendency to be inattentive. However, parental education level was the strongest predictor of grade-school performance and classroom behavior in all analyses. Further research is warranted utilizing objective measures of habitual physical activity paired with physical activity questionnaires. This will account for the lack of sensitivity in activity monitors in picking up certain activities. Also, objective measures of academic performance, such as students' grade point average, and more definitive definitions of school behaviors should be used to determine the true extent of the associations. 


\section{REFERENCES}

1. Ardoy DN, Fernández-Rodríguez JM, Jiménez-Pavón D, Castillo R, Ruiz JR, Ortega FB. A physical education trial improves adolescents' cognitive performance and academic achievement: the EDUFIT study. Scand J Med Sci Sports. 2014; 24(1): e52-61.

2. Baker JL, Olsen, LW, Sørensen, TIA. Childhood body-mass index and the risk of coronary heart disease in adulthood. N Engl J Med. 2007; 357(23): 2329- 37.

3. Bass RW, Brown DD, Laurson KR, Coleman MM. Physical fitness and academic performance in middle school students. Acta Paediatrica. 2013; 102(8): 832-7.

4. Castelli DM, Hillman CH, Buck SM, Erwin HE. Physical fitness and academic achievement in third- and fifth-grade students. J Sport Exerc Psychol. 2007; 29(2):239-52.

5. CDC - Overweight Prevalence Among Children and Adolescents 2011-2012 [Internet]. Atlanta (GA). Centers for Disease Control and Prevention; [cited 2015 February 26]. Available from:

http://www.cdc.gov/nchs/data/hestat/obesity_child_11_12/obesity_child_ 11 12.htm.

6. CDC-Youth Online: Middle School YRBS 2013 Results [Internet]. Atlanta (GA). Centers for Disease Control and Prevention; [cited 2015 February 26]. Available from: http://nccd.cdc.gov/youthonline/App/Results.aspx.

7. Chaddock L, Erickson KI, Prakash RS, et al. A neuroimaging investigation of the association between aerobic fitness, hippocampal volume, and memory performance in preadolescent children. Brain Res. 2010; 1358: 172-83.

8. Cotman CW, Engesser-Cesar C. Exercise enhances and protects brain function. Exerc Sport Sci Rev. 2002; 30(2): 75-9.

9. Datar A, Sturm R. Childhood overweight and elementary school outcomes. Int J Obes (Lon). 2006; 30(9): 1449-60.

10. Davis CL, Tomporowski PD, Boyle CA, et al. Effects of aerobic exercise on overweight children's cognitive functioning: a randomized controlled trial. Res Q Exerc Sport. 2007; 78(5): 510-9.

11. Eisenmann JC, Gentile DA, Welk GJ, et al. SWITCH: rationale, design, and implementation of a community, school, and family-based intervention to modify behaviors related to childhood obesity. BMC Public Health [Internet]. 2008 [cited 2015 February 11] 8. Available from: http://www.ncbi.nlm.nih.gov/pmc/articles/PMC2474862/. doi: 10.1186/1471-2458-8-223. 
12. Grieco LA, Jowers EM, Bartholomew JB. Physically active academic lessons and time on task: the moderating effect of body mass index. Med Sci Sports Exerc. 2009; 41(10): 1921-6.

13. Guiney H, Lucas SJ, Cotter JD, Machado, L. Evidence cerebral blood-flow regulation mediates exercise-cognition links in healthy young adults. Neuropsychology. 2015; 29(1): 1-9.

14. Judge S, Jahns L. Association of overweight with academic performance and social and behavioral problems: an update from the early childhood longitudinal study. J Sch Health. 2007; 77(10): 672-8.

15. Kwak L, Kremers SPJ, Bergman P, Ruiz JR, Rizzo NS, Sjöström, M. Associations between physical activity, fitness, and academic achievement. J Pediatr. 2009; 155(6): 914-8.

16. LeBlanc MM, Martin CK, Han H, et al. Adiposity and physical activity are not related to academic achievement in school-aged children. J Dev Behav Pediatr. 2012; 33(6): 486-94.

17. Lee SM, Burgeson CR, Fulton JE, Spain CG. Physical education and physical activity: results from the school health policies and programs study 2006. $J$ Sch Health. 2007; 77(8): 435-63.

18. London RA, Castrechini S. A longitudinal examination of the link between youth physical fitness and academic achievement. J Sch Health. 2011; 81(7): 400-8.

19. Mahar MT, Murphy SK, Rowe DA, Golden J, Shields AT, Raedeke TD. Effects of a classroom-based program on physical activity and on-task behavior. Med Sci Sports Exerc. 2006; 38(12): 2086-94.

20. Matthews CE, Chen KY, Freedson PS. Amount of time spent in sedentary behaviors in the United States, 2003-2004. Am J Epidemiol. 2008; 167(7): 87581.

21. Pellegrini AD, Huberty PD, Jones I. The effects of recess timing on children's playground and classroom behaviors. Am Educ Res J. 1995; 32(4): 84564.

22. Rauner RR, Walters RW, Avery M, Wanser TJ. Evidence that aerobic fitness is more salient than weight status in predicting standardized math and reading

outcomes in fourth- through eighth-grade students. J Pediatr. 2013; 163(2): 344-8.

23. Reed JA, Einstein G, Hahn E, Hooker SP, Gross VP, Kravitz J. Examining the impact of integrating physical activity on fluid intelligence and academic performance in an elementary school setting: a preliminary investigation. $J$ Phys Act Health. 2010; 7(3): 343-51.

24. Roberts CK, Freed B, McCarthy WJ. Low aerobic fitness and obesity are associated with lower standardized test scores in children. J Pediatr. 2010; 156(5): 711-8.

25. Srinivasan SR, Myers L, Berenson GS. Predictability of childhood adiposity and insulin for developing insulin resistance syndrome (syndrome $\mathrm{X}$ ) in young adulthood: the Bogalusa Heart Study. Diabetes. 2002; 51(1): 204-9. 
26. Syväoja HJ, Kantomaa MT, Ahonen T, Hakonen H, Kankaanpää A, Tammelin TH. Physical activity, sedentary behavior, and academic performance in Finnish children. Med Sci Sports Exerc. 2013; 45(11): 2098-104.

27. Van Dusen DP, Kelder SH, Kohl HW, Ranjit N, Perry CL. (2011). Associations of physical fitness and academic performance among schoolchildren. $J$ Sch Health. 2011; 81(12): 733-40.

28. Whitaker RC, Wright JA, Pepe MS, Seidel KD, Dietz WH. Predicting obesity in young adulthood from childhood and parental obesity. $N$ Engl J Med.

1997; 337(13): 869-73. 